\title{
An integrated GIS-based tool for aquifer test analysis
}

\section{R. Criollo, V. Velasco, E. Vázquez-} \section{Suñé, A. Serrano-Juan, M. Alcaraz \&}

\section{A. García-Gil}

\section{Environmental Earth Sciences}

ISSN 1866-6280

Volume 75

Number 5

Environ Earth Sci (2016) 75:1-11

DOI 10.1007/s12665-016-5292-3

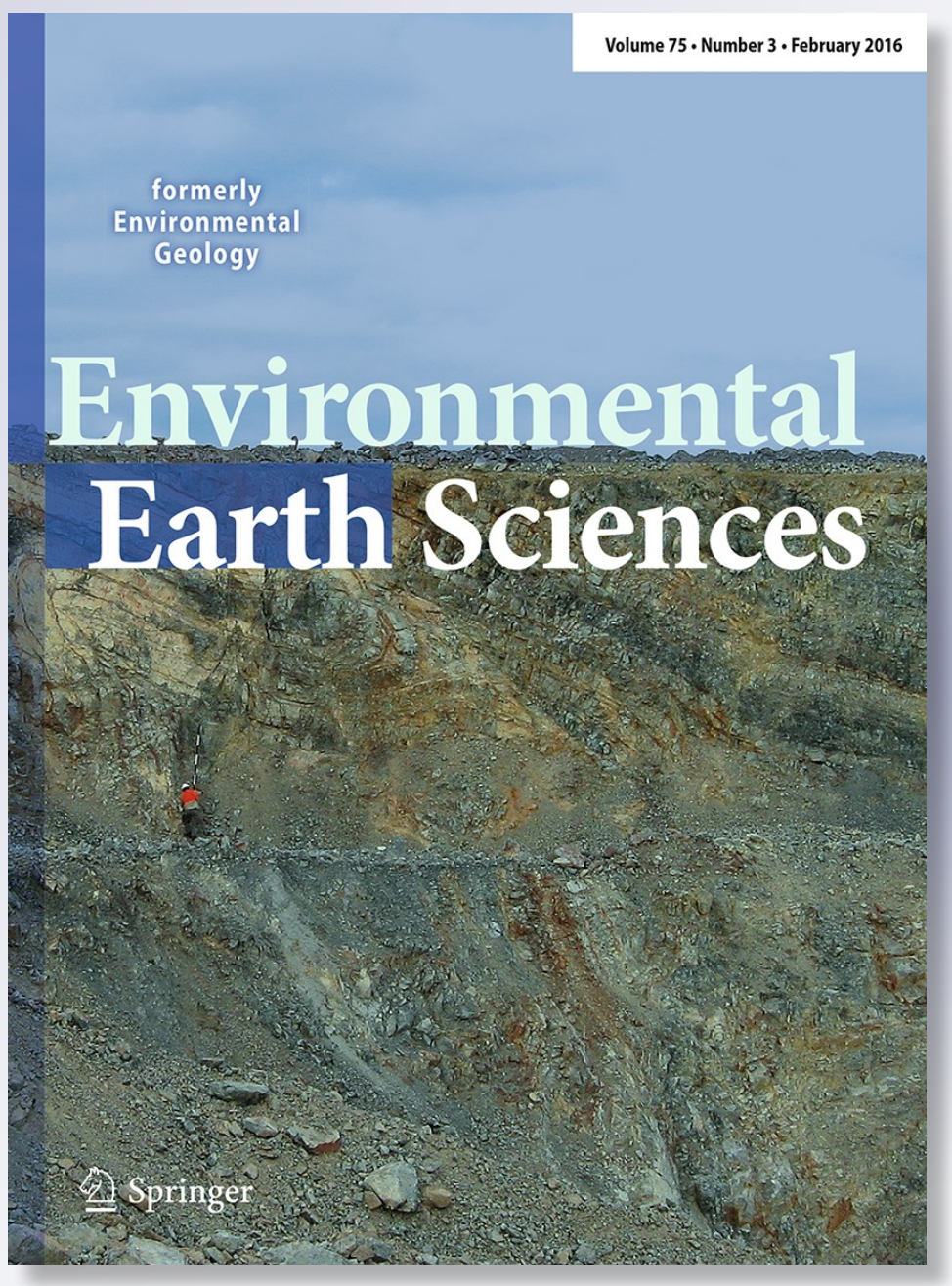

望 Springer 
Your article is protected by copyright and all rights are held exclusively by SpringerVerlag Berlin Heidelberg. This e-offprint is for personal use only and shall not be selfarchived in electronic repositories. If you wish to self-archive your article, please use the accepted manuscript version for posting on your own website. You may further deposit the accepted manuscript version in any repository, provided it is only made publicly available 12 months after official publication or later and provided acknowledgement is given to the original source of publication and a link is inserted to the published article on Springer's website. The link must be accompanied by the following text: "The final publication is available at link.springer.com". 


\title{
An integrated GIS-based tool for aquifer test analysis
}

\author{
R. Criollo ${ }^{1,2,3}$ (1) V. Velasco ${ }^{3,4} \cdot$ E. Vázquez-Suñé $e^{3,4} \cdot$ A. Serrano-Juan ${ }^{2,3,4}$. \\ M. Alcaraz $z^{2,3,4} \cdot$ A. García-Gil ${ }^{3,5}$
}

Received: 22 June 2015/ Accepted: 16 November 2015

(C) Springer-Verlag Berlin Heidelberg 2016

\begin{abstract}
The quantification of the hydraulic parameters is important to support decision making in environmental impact assessment, water resources evaluation or groundwater contamination remediation, among others. These kind of parameters derived from aquifer tests usually encompasses a vast amount of data (spatial and non-spatial) for management and analysis. To achieve this in a clear and understandable manner, the GIS environment is a useful instrument. Development of innovative software to analyze pumping tests in a GIS platform environment to support the hydraulic parameterization of groundwater flow and transport models is presented in this paper. This new platform provides three interconnected modules to improve (a) pumping test interpretation code through a user-friendly interface, (b) pumping test data visualization supported by a set of tools that perform spatiotemporal queries in a GIS environment and (c) the storage and management of
\end{abstract}

Electronic supplementary material The online version of this article (doi:10.1007/s12665-016-5292-3) contains supplementary material, which is available to authorized users.

R. Criollo

rcriollo@bcn.cat; rotman.criollo@idaea.csic.es

1 Department of Civil and Environmental Engineering, Universitat Politècnica de Catalunya (UPC), C/Jordi Girona 1-3, 08034 Barcelona, Spain

2 Barcelona Cicle de l'Aigua SA (BCASA), C/de l'Acer 16, 08038 Barcelona, Spain

3 Hydrogeology Group (UPC-CSIC), Barcelona, Spain

4 Institute of Environmental Assessment and Water Research (IDAEA), CSIC, C/Jordi Girona 18-26, 08034 Barcelona, Spain

5 Department of Earth Sciences, University of Zaragoza, C/Pedro Cerbuna 12, 50009 Zaragoza, Spain hydrogeological information. Additionally, within the GIS platform, it is possible to process the hydraulic parameters obtained from the pumping test and to create spatial distribution maps, perform geostatistical analysis and export the information to an external software platform. Finally, a real-world application in the area of Barcelona (Spain) has shown the usefulness of the tools developed in support of hydrogeological analysis.

Keywords GIS · Excel · Aquifer characterization · Hydrogeological analysis - Pumping test

\section{Introduction}

The quantification of hydraulic parameters such as transmissivity $(T)$, hydraulic conductivity $(K)$, storativity $(S)$, and specific storage $(S \mathrm{~s})$ is important for hydrogeological assessments and for the development of groundwater flow and transport models to support decision making in environmental impact assessment, groundwater contamination remediation, water resources evaluation or site monitoring (Rogiers et al. 2012).

There are several methods to determine hydraulic parameters. The selection of a suitable method depends on the purpose of the research and the required degree of accuracy (Vukovic and Soro 1992). The pumping test is the most commonly used method to obtain aquifer parameters and generally leads to reliable hydraulic parameters. The reliability of the results depends on many factors such as the following: (1) availability of wells and observation points for testing, (2) quality of the pumping test and the subsequent management and analysis of the data obtained and (3) accurate information of aquifer geometry and hydraulic boundaries (Cheong et al. 2008). Furthermore, a 
number of specific issues must be considered when dealing with aquifer tests. On the one hand, each problem requires specific solutions (different hydrogeological conditions, different results, different study area and wellbore characteristics, etc.). On the other hand, regarding aquifer test interpretation, a selection of the proper graphical, analytical and numerical solutions for the interpretation should be considered. Moreover, the use of full or partial datasets for the analysis should be taken into account. In this sense, the use of comprehensive tools to store, manage and visualize the vast amount of available data becomes a necessity to focus the analysis and leads to an accurate interpretation.

Therefore, it is not surprising that, currently, there is a great amount of software oriented to manipulate and facilitate the calculations of hydraulic parameters from aquifer tests. These computer tools reduce the calculation time and allow a better and more accurate determination of hydraulic parameters. For instance, WTAQ (Barlow and Moench 1999), WIGAEM (Bakker 2009) or WELLS (Vesselinov 2009) apply analytical solutions for pumping test analysis, but there is still a lack of tools for the pre- and post-processing of input and output data. This is an important problem to be solved because the size of the datasets to be processed is continuously increasing. This growth is closely linked to the importance of water resources, which is becoming more crucial for human communities and because of the greater complexities of the regional groundwater numerical models being used currently. In addition, the hydraulic data available for integration into groundwater numerical models usually has a very diverse origin and format and, therefore, a chance of bias in the interpretations. Consequently, it becomes necessary to have effective instruments that facilitate the pre-process, the visualization, the analysis and the validation (e.g., graphical analysis techniques) of this great amount of data.

Software platforms such as MATLAB ${ }^{\circledR}$ or MS Excel ${ }^{\circledR}$ seem to be more appropriate environments for pre- and post-processing hydrogeological data because of their rich set of tools that are oriented to analyze and visualize data results. Additionally, these software platforms provide a graphical user interface (GUI) for developing specific tools. Some applications oriented to aquifer test data analysis have been developed in the MATLAB ${ }^{\circledR}$ environment such as HYTOOL (Renard 2003) or CHOW (Zhan et al. 2001), which provide a user-friendly interaction with the scripts for aquifer test analysis. In the same way, MS Excel $^{\circledR}$ is a spreadsheet program that allows analysis and plotting of input and output data by using its built-in functions and its Visual Basic for Application (hereinafter VBA) macro option. Some examples of specific tools for pumping test data analysis developed in this context are USGS Spreadsheets by USGS (Halford and Kunianksy 2004), Molano (2013) or Johnson and Cosgrove (2001). In addition, the latter can make drawdown contours and mass balance graphs of RADFLOW code.

Computer programs that incorporate additional methodologies to process, visualize and interpret aquifer test data give one step beyond. Some examples are AQTESTSOLV (Duffield 1989), Well32 (Geo\&soft 1993), AquiferWin32 (Rumbaugh and Rumbaugh 1997), Aquifer Test (Röhrich and Hydrogeologic 2002) or MLU (Hemker and Post 2009). While these software contains many powerful features for performing aquifer tests analysis, further developments in the management of large datasets provided by the aquifer tests and by its interpretations would significantly improve the resulting hydraulic parameterization of the study area. Besides an appropriate storage of all available data and documentation of the procedures used for the interpretation of the pumping tests will facilitate the further updating of the initial parameterization of the hydrogeological model and will also guarantee its future reuse by third parties for different objectives. In this regard, additional advances have been achieved by software such as PIBE (Diputación de Alicante 2006) or EPHEBO (UPC 2002).

Despite of these advances, further analysis should be focused on improving the interpretation and validation of the hydraulic parameterization provided by aquifer tests such as the cross-analysis with other datasets (e.g., aquifer geometry or hydraulic boundary conditions). In this sense, the use of a Geographical Information System (GIS) environments represent an optimal solutions for the integration of the aquifer tests data with other relevant datasets (e.g., geological or meteorological datasets) and enable the straightforward queries, search and retrieval of portions of information provided by different sources. Common GIS applications for groundwater research include tools that generate spatiotemporal queries of different hydrogeological parameters. ArcHydro (Maidment 2002; Strassberg 2005), CUAHSI (Maidment 2005) or GMS (EMRL 2004) are examples of these types of GIS-based tools, which take advantage of the GIS platforms to manipulate and visualize aquifer information, giving another dimension to the analysis process.

By emphasizing pumping tests and decision making GIS-based tools, Yang and Lin (2011) developed software (uWATER-PA) for non-specialized issues of groundwater pumping impacts limited by one specific analytical solution for calculations.

The foregoing improvements to analyze, visualize and interpret aquifer tests constitute a relevant advantage for the estimation of hydraulic parameters over traditional analysis. However, additional refinements are still needed such as storing, managing and analyzing all the available data provided by the aquifer tests interpreted by different methods into a GIS environment. Indeed, the main objective of this work is to provide these needed refinements. To 
perform that, we provide a package of tools for collecting, managing, analyzing, processing and interpreting data derived from pumping tests in a GIS environment. In this sense, the tools developed allow us to apply different methods to interpret aquifer test data in several scenarios taking into account all the information available related with the study zone. Using the standardized spatial database aids to a proper data management. This will increase the understanding and the knowledge in the study area and, thus, will help the development of future projects.

The paper is distributed as follows: design and features of the developed software are briefly described in section "Pumping test software platform". In section "Application: urban area of barcelona (spain)", an application of these tools in a study area is presented and, finally, the conclusions are presented together with additional discussion on the advantages and disadvantages of the software.

\section{Pumping test software platform}

To facilitate the management and interpretation of pumping tests in a GIS environment, four main requirements should be considered: (a) storing and managing hydrogeological data related to pumping tests in an uniform structure, (b) pumping test data processing and visualization in a GIS environment, (c) specific tools to interpret or re-interpret pumping tests considering different methods and (d) interoperability with external software for further analysis to complete hydrogeological studies. These requirements mentioned have been reached by the methodology used in the next section.

\section{Software design}

To develop the software platform presented in this paper, the following technical criteria were used as guidelines:

(1) A geospatial database to integrate the sets of data from pumping tests. The developed database requires tools and methodologies to simplify the end-user's tasks (user interface and protocols for data exchange).

(2) GIS environment with the following characteristics:

a. Suite of inherent tools in a GIS environment (e.g., mapping, georeferencing, geostatistical tools, etc.).

b. Specialized tools to analyze and integrate hydrogeological data (e.g., to consult points involved in the test, pumping test duration, parameter values estimated, etc.) fed by a structured database.

(3) Interoperability with external software for further analysis such as aquifer test analysis.

(4) Statistics tools, filters and queries, and different methodologies to solve different aquifer scenarios to guarantee an optimal interpretation.
(5) Post-processing tools. Once the interpretation of pumping tests with external software is performed, the results should be imported again into the GIS platform to continue with the spatial analysis (e.g., useful to prepare maps of parameters to export them to a modeling package). In addition, this analysis can be supported by accurate information on aquifer geometry, hydraulic boundaries (Cheong et al. 2008) or other spatiotemporal data in a clear and understandable manner.

\section{Software features}

The presented work forms part of a wider on-going framework to facilitate detailed hydrogeological modeling that includes additional hydrochemical and geological GIS-based analysis tools and a geospatial database termed HYDOR. These tools are described in Velasco et al. (2012a, b, 2014), Velasco (2013).

The innovative set of analysis tools and methodologies oriented to analyze, visualize and interpret aquifer test data are explained above. This set of tools was developed as a set of modules, which are interconnected to each other and simplifies the end-user's tasks through the integration of (1) a module for the analysis of pumping tests (MJ-Pumpit), (2) a geospatial database to record and manage data involved in pumping tests (HYDOR) and (3) tools for advanced spatiotemporal analysis built in the same GIS environment (HYYH toolbar) (see Fig. 1). The module integration is possible thanks to the compatibility among the software platforms used into build each module. An optimal workflow is possible preserving a complete data control with the geodatabase.

\section{MJ-Pumpit}

MJ-Pumpit is a GUI for MariaJ code (Carbonell et al. 1997), hereinafter MJ, which simplifies the data handling and model selection needed to execute MJ code. Thus, MJPumpit has been developed as a MS Excel Add-in, programed in VBA, following the methodology proposed by

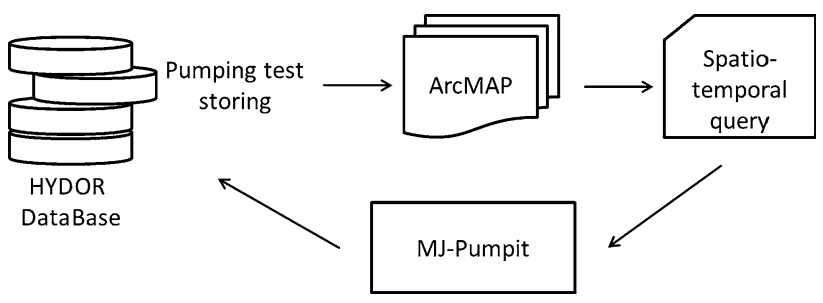

Fig. 1 Software architecture. Data for the spatiotemporal query and for MJ-Pumpit are managed by the spatial database and visualized in the GIS platform 
Serrano-Juan et al. (2015). The use of MS Excel spreadsheets as a platform is based on the following reasons: (a) it is a highly stable software, (b) it is a widely used software, (b) it ensures a portable and easily handled format; (c) it allows an easy performance of data queries (e.g., to check potential mistakes), analyses and plots; (d) it has a userfriendly interface to create numerical and statistical computations, among others. In this way, MJ-Pumpit has the available MS Excel tools to analyze and plot data to ease the pumping test interpretation with analytical models for different aquifer scenarios included in MJ code.

The MJ code (FORTRAN-based) is a software for automatic calibration of pumping test, which includes several analytical models to interpret the test. It obtains the best aquifer parameters for the considered model and fits the results obtained with the observations data by minimizing the objective function. Input data, statistical analysis and information about the iteration process are printed in the output file, which is also uploaded into MJ-Pumpit and displayed automatically.

MJ-Pumpit allows the user to load pumping test data by using its own query interface. Additionally, a command developed directly in the GIS platform (see section "Pumping test analysis tool") enables retrieving the information for the selected wells and time intervals by exporting data into MJ-Pumpit, adding a previous spatiotemporal analysis.

MJ-Pumpit features The GUI of MJ-Pumpit is composed of different commands that facilitate the interpretation process of pumping tests and allows the following:

- Interchange data with HYDOR database through the GIS platform. Export/import the pumping test data and its interpretation from or to MJ-Pumpit.

- Error typing avoidance during the field data insertion process.

- Field data quality analysis improvement in MS Excel before executing the code.

- Ensuring an appropriate selection of the conceptual model using diagnostic plots.

- The integration of different aquifer scenarios by different methodologies of pumping test analyses and other characteristics are available such as edges (recharge or waterproof), pumping well loss, double porosity, among others (see Fig. 2).

- The results are displayed from the iterative process through automatically generated reports and graphical plots of fitted and measured values (Fig. 3). Their formats can be changed per the user's requirements with MS Excel capabilities.

- MJ-Pumpit can be used in six different languages.

\section{Spatial database}

The spatial database HYDOR was developed by following the structure of a Personal Geodatabase (ArcGIS, ESRI 2004) and it was created following international standards and taking into account other hydrogeological databases. Its relational structure aims to store, operate and relate several topics in different datasets to manage geological, hydrochemical and hydrogeological, hydrological, geophysical and meteorological information. In addition, to standardize and harmonize the information collected, the HYDOR geodatabase allows insert data in different formats following a protocol that was developed to import a large volume of data at the same time or "one by one". For further information about HYDOR see Velasco et al. (2012b, 2014), Velasco (2013).

Although the data model of the hydrogeological database described here was implemented within ArcGIS (ESRI 2004), most of these concepts are sufficiently flexible to enable implementation in other platforms (Velasco et al. 2014).

Developed in the same way, regarding the information on pumping tests, a group of tables have been created to support the storage and management of its data. In this sense, to facilitate data handling for any user, the pumping test information that is collected is separated into different datasets:

- Geographic features stored in DB_Points table (e.g., point names, coordinates, source of information, etc.).

- Specific characteristics of wells such as radius, depth or screens are collected in DB_Wells table.

- Test characteristics and observations are included in DB_PumpingTestSpecifications and DB_PumpingTestObservations tables (e.g., flow and drawdown timings, cumulative volumes, pumping well, etc.).

- Pump characteristics are collected in DB_Pumps.

- Initial interpretations or interpretations made with MJPumpit are located in DB_PumpingTestInterpretations.

Additionally, to ensure the standardization of data recorded in the database, different topics are arranged into list codes such as test types, units of measure or relevant data (e.g., type of pumping test), and additional details of the test, among others, are compiled. A simplified entity relationship diagram for the database structure is presented in Fig. 4 and shows the interaction between the measurements, pump characteristics and pumping test interpretations. To ensure the right database functionality, the environment has mechanisms to facilitate data transcription and to avoid its inconsistency during their insertion. Other specialized tools to simplify the spatial and temporal queries of pumping test data will be discussed below. 
Fig. 2 MJ-Pumpit the model selection spreadsheet introduces several models of aquifer environments (buttons on the left; in this case, the Barker (1988) model is selected and has different options available such as well pumping storage, skin factor, and anisotropy, among others)

Fig. 3 MJ-Pumpit: results spreadsheet allows us to analyze the MJ iteration process (panel a), plots of fitted values (panel $b$ ) and export parameter values to the HYDOR database for additional spatiotemporal analysis in a GIS environment
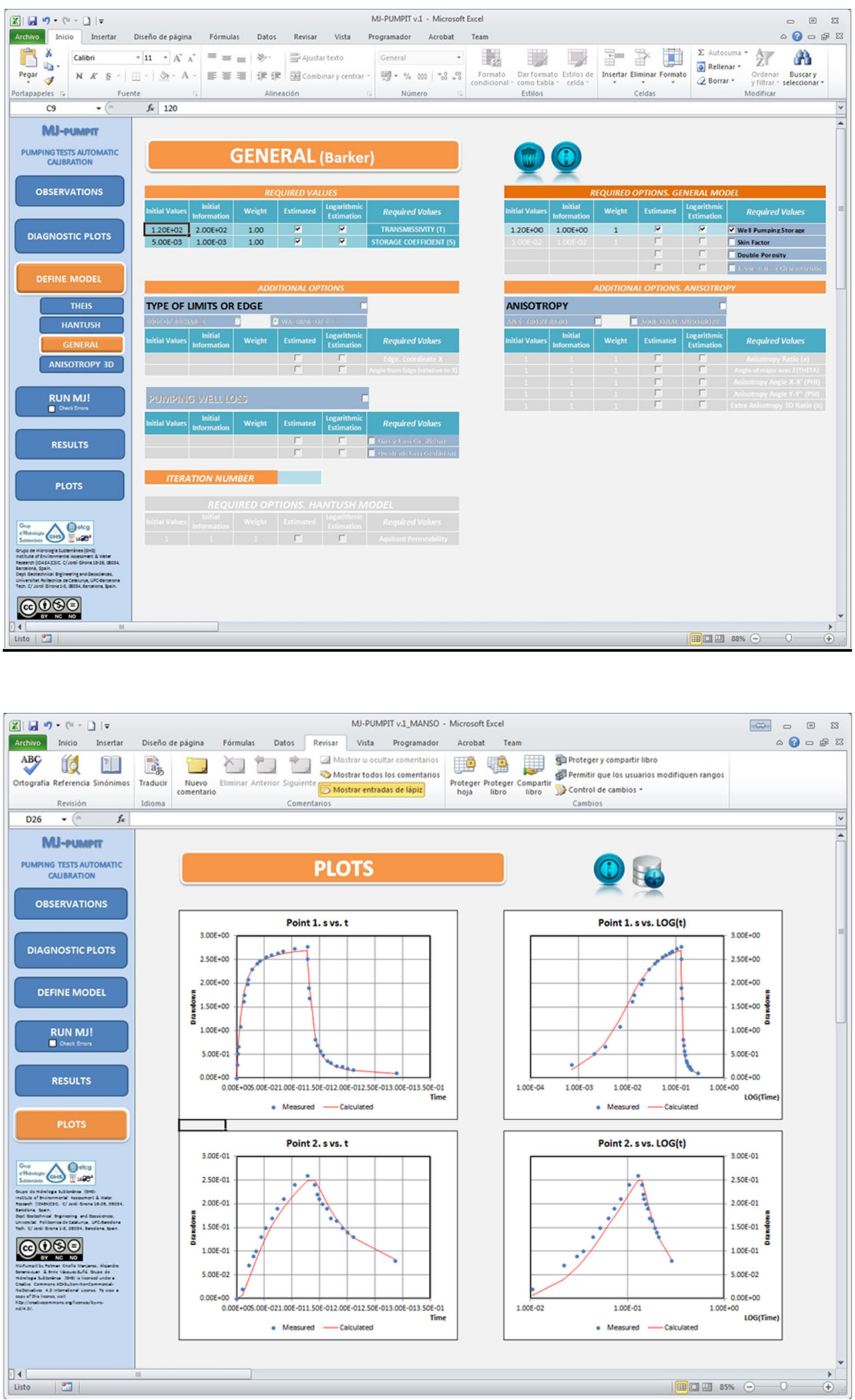
Fig. 4 The conceptual diagram represents the main fields that comprise the hydrogeological database referred to in the pumping test. The 1 and $1 *$ represent the cardinality of the relationship between tables

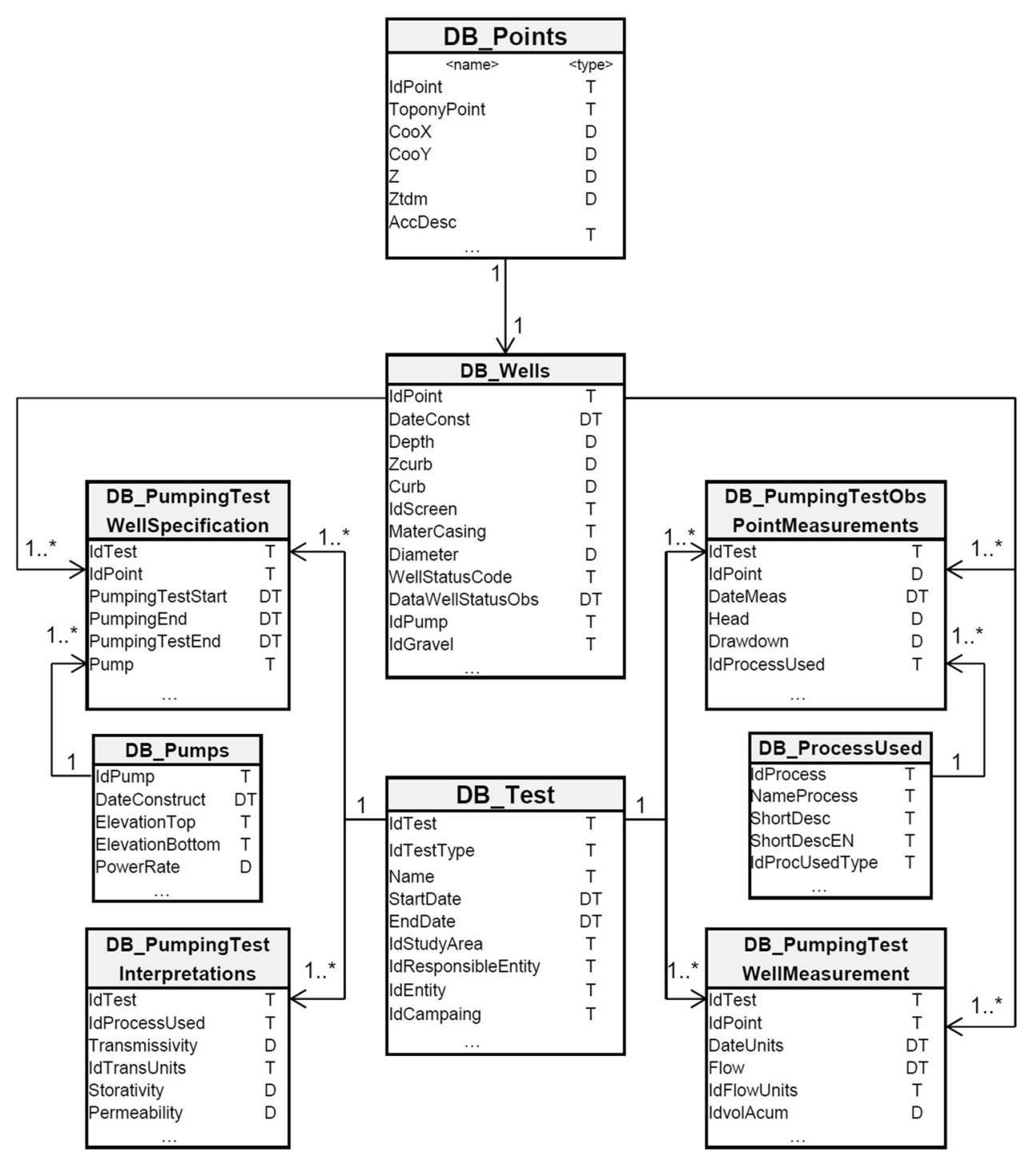

\section{Spatiotemporal query tools}

The spatiotemporal tools developed in the present work are an extension of the HYYH toolbar, which was designed to analyze and visualize different hydrogeological measurements and the results of field tests (including pumping tests) stored in the HYDOR database for a complete hydrogeological analysis. The different tools integrated in the HYYH toolbar are shown in Fig. 5 and fully described in the following sections (from section "Hydrogeological data analysis" to section "Pumping test analysis tool"). These tools were created with ArcObject, a developer kit based on the Component Object Model (COM) by using the Visual Studio ${ }^{\circledR}$ (2010 version). These platforms were selected because: (1) it allow reuse and use external objects as their own, (2) its large set of standards for implementing and using objects and for inter-object communication, (3)
COM offer interact across process and computer boundaries as a easily manner within a single process, among others (Microsoft 2014).

Hydrogeological data analysis tools This set of tools makes queries regarding the evolution of the piezometric levels and the control of the aquifer abstractions (see Fig. 5). This information can be analyzed individually or jointly with other information stored in the database. The temporal query can discretize the evolution of the desired parameter by displaying the information such as campaign name, measurement date or measure point in a table. For further analysis, the user can display the temporal evolution of the data selected (Graph command), export data to MS Word (RTF Report command), export data to MS Excel (Excel Report command), or use the Create Map command. The functionality of the latter command is used to calculate 


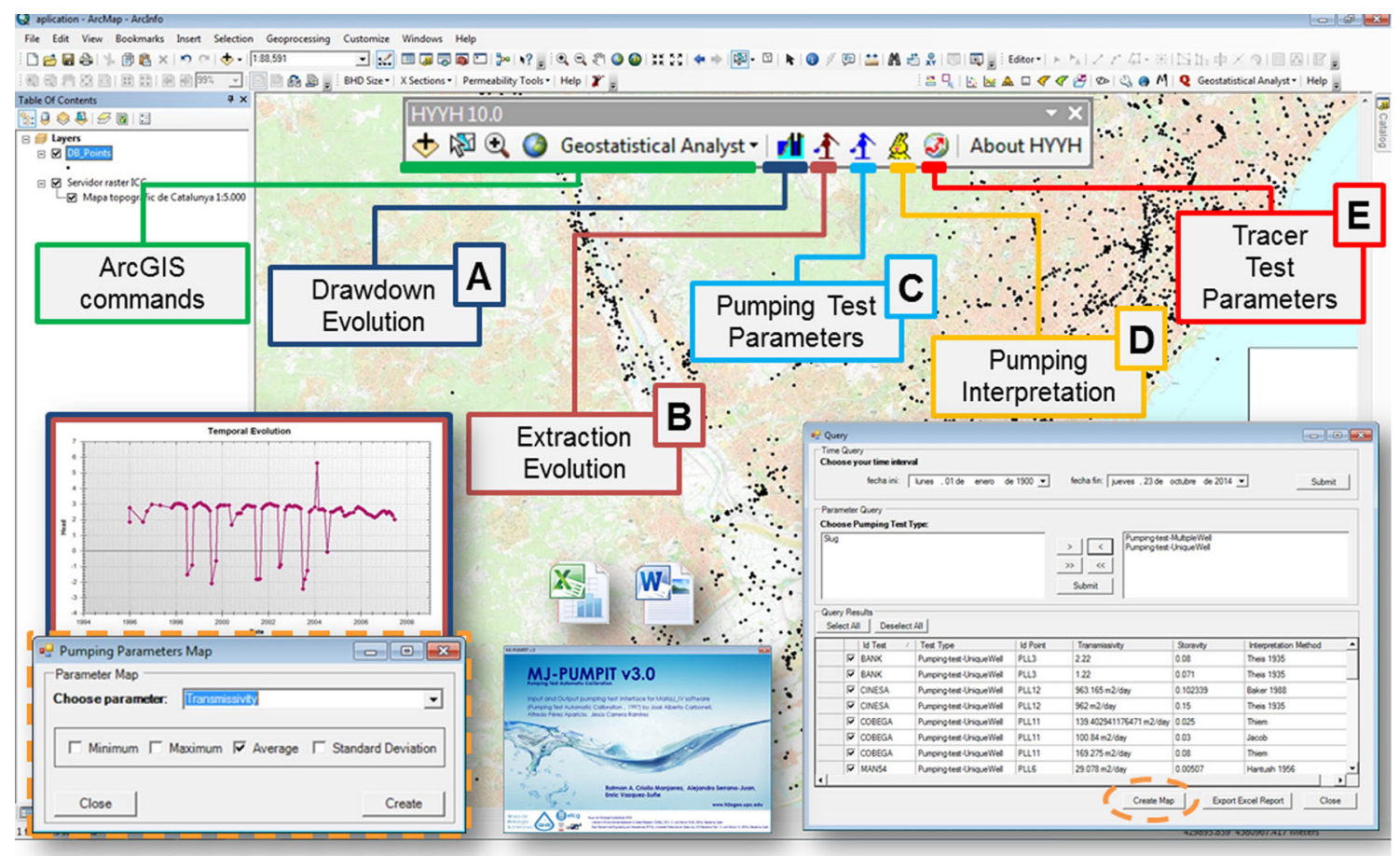

Fig. 5 Scheme of HYYH toolbar tools available in ArcMAP. Hydrogeological data analysis tools ( $A$ and $B$ tools) and hydrogeological test analysis tools $(C, D$ and $E$ tools) have specialized

basic statistical data (minimum, maximum, average and standard deviation), after to be selected the required points in the screen, for each selected parameter for a given period of time. These values are displayed in a shapefile, which can be used for future geostatistical analysis through the geostatistical analyst tools inherent in ArcGIS without leaving the platform.

Hydrogeological test analysis tools As stated above, the selection of the pumping tests (see Fig. 5) is performed by choosing a set of points on the screen that represents points involved in a given aquifer test. The analysis tools of the hydrogeological test (tracer and pumping test interpretations) allow to visualize the data stored in the database with the spatio-temporal query. Once the temporal discretization query of the selected points in the ArcMap (ESRI) is performed, a list of data related to the hydrogeological test is given. This data, such as campaign name, date of test, parameter values obtained by different aquifer field tests, among others, can be exported to other platforms (MS Excel or MS Word) and make effective reports or create maps of statistical values of the selected parameter for additional uses (e.g., hydraulic parameter maps to be exported to the numerical model, see Fig. 6). commands to export data selected for other platforms, temporal evolution plots, and created parameter maps

If there are one or more pumping tests without interpretations or with old interpretations in the study area, the user can make a new pumping test analysis simply and quickly with the tool presented below.

Pumping test analysis tool This command has been developed to analyze pumping test data involved during the test, which is composed of the following commands.

Querying the test data. Similar to the previous sections, the spatial and temporal discretization of the study area gives a list of several available fields in the database related to pumping tests (e.g., test name, interval time, or number of points involved in the test). For each test selected, the information can be exported to another platform to make reports (MS Word or MS Excel) or to interpret the test with MJ-Pumpit.

Link to MJ-Pumpit. This command allows the export/ import of selected tests and related data for a new interpretation to or from the MJ-Pumpit GUI. Once a user obtains the hydraulic parameters with MJ-Pumpit, it is possible to load them back into the GIS platform (storing the analysis data and results in the geospatial database) and to reinforce the hydrogeological study by complementing it with other datasets (see Fig. 7 as an example) for a 


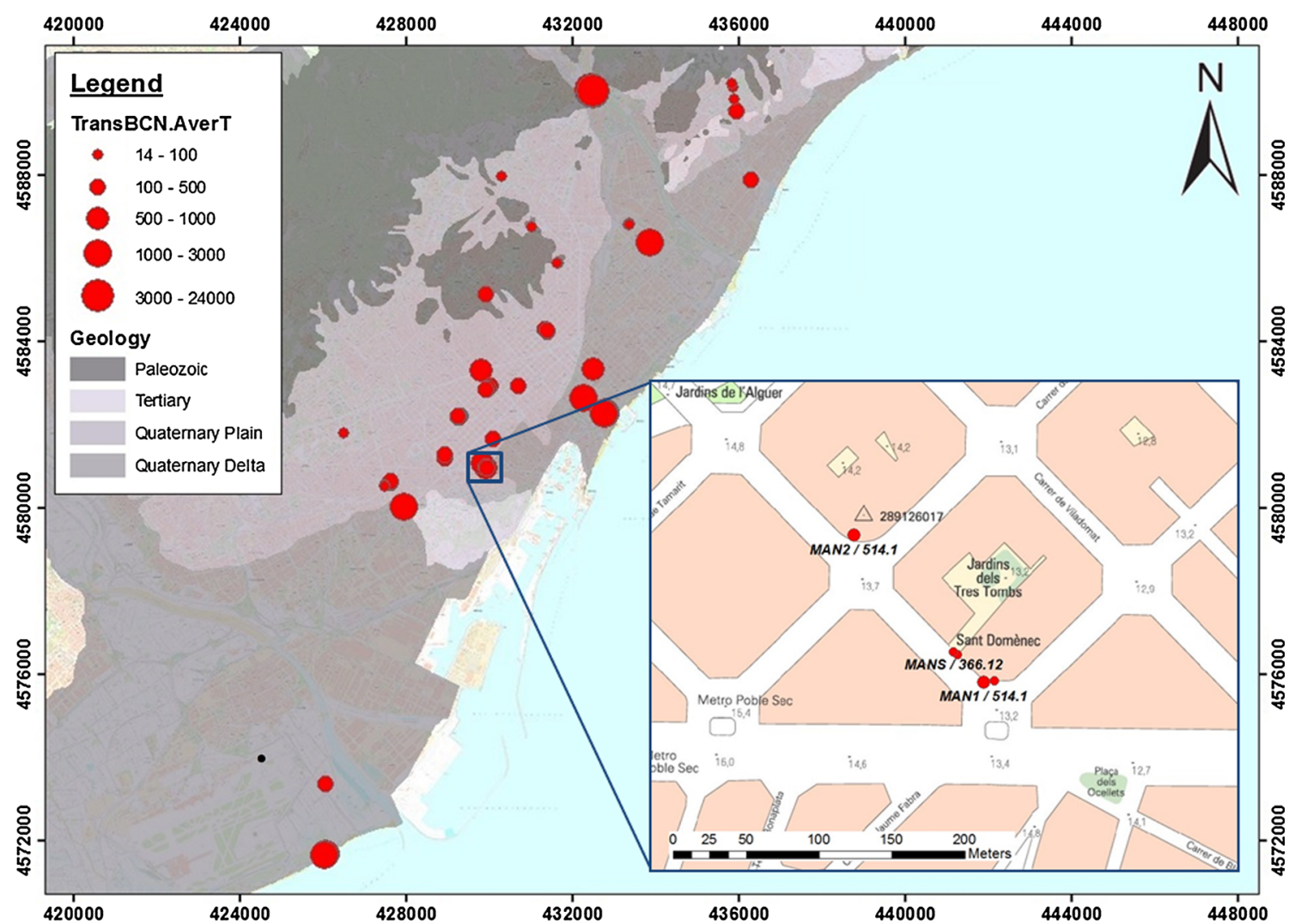

Fig. 6 Transmissivity map $\left(\mathrm{m}^{2} /\right.$ day) created by the hydrogeological test analysis tools. These types of maps can aid the modelling groundwater flow and solute transport. With geostatistical wizards

complete hydrogeological analysis using other information treated with the tools described above.

\section{Application: urban area of barcelona (spain)}

The designed software has been applied in The Metropolitan area of Barcelona, which is located in northeastern Spain (Fig. 7). Barcelona is limited by the Serra de Collserola (NNE), the Mediterranean Sea (SSW) and two rivers: Besòs (NE) and Llobregat (SW). The latter is delimited by Montjuïc hill next to the seashore. From the geological characteristics, different hydrogeological units can be identified: Paleozoic materials, made by shales and granites, are located in the high part of the city; Montjuic hillslope made up of marls, sandstones and sands from Tertiary period; and Quaternary aquifers which can be separated in alluvial—deltaic sediments in topographic low areas and piedmont cones-coarse alluvial sediments located in the intermediate areas (Vázquez-Suñé 2003). Barcelona's aquifers suffered heavy water extractions from the XIXth century until the 1970s when many industries migrated from the city to other areas. These continuous decreases in groundwater extractions, at the same time, available in ArcGIS, users can extrapolate this information and create surface maps for additional uses

have caused increases in water levels (Vázquez-Suñé et al. 2005). Currently, several aquifers have mainly secondary uses, such as garden irrigation and maintenance or street cleaning, but they can be considered alternative tap water resources (Jurado et al. 2014).

The information available in the HYDOR database was obtained in different formats (paper, images and digital formats) from several hydrogeological (e.g., Vázquez-Suñé et al. 2005), hydrochemical (e.g., Jurado et al. 2014), geological (e.g., Velasco et al. 2012a, Velasco 2013) and civil engineering works, which can be used for future hydrogeological models, re-interpretations, and comparisons. Thus, the database stores over 1443 boreholes, 3700 groundwater points and 19 weather stations. Data related to each point are in Table 1 (for additional information on the data and their sources see Velasco 2013). In particular, in terms of pumping test data, the Barcelona database includes 70 points related to 32 pumping tests distributed in the study area (Fig. 7).

The analysis and the interpretation of the pumping tests were performed following the next steps, which can be used as a methodology to apply the software presented in this paper.

The first step was analyzed and visualized the spatial variability of the hydraulic parameters. MJ-Pumpit (see 


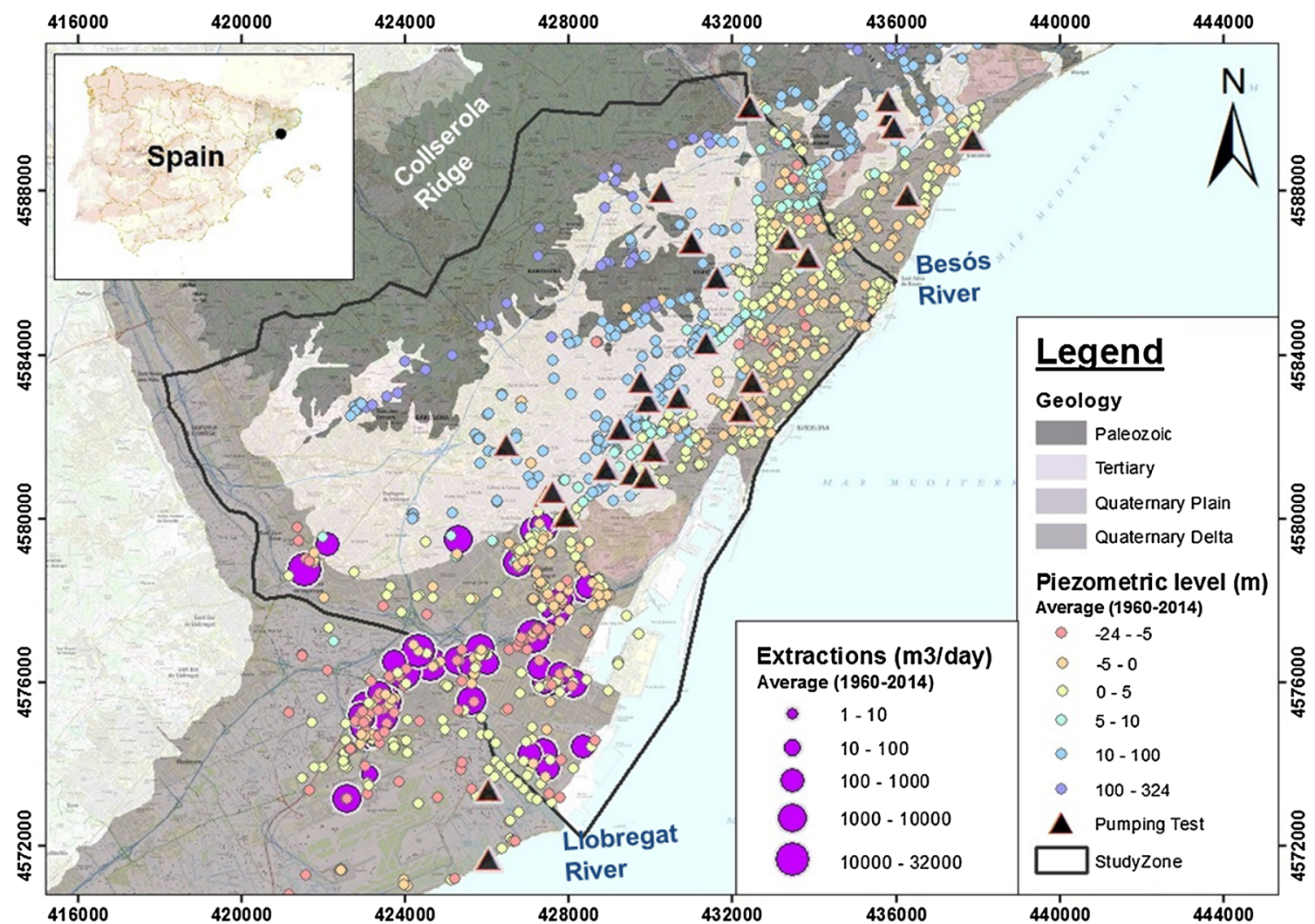

Fig. 7 Geological map of the Metropolitan Area of Barcelona (Spain) (IGC, Institut Geològic de Catalunya) with extractions, piezometric levels and pumping tests stored in the HYDOR database

Table 1 Resume of data stored in the Barcelona database

\begin{tabular}{llllllll}
\hline Hydrogeology & Points & Piezometric measures & Extraction measures & Pump test & Flow steps & Pump observations & Pump interpretations \\
\hline \multirow{2}{*}{3778} & 52,038 & 19,717 & 32 & 1965 & 63,908 & 77 \\
\hline
\end{tabular}

section "Pumping test analysis tool") was used to evaluate the availability of pumping tests in the selected area for the selected time period (1960-2014). As result, we automatically obtained necessary information to check which tests have been already interpreted (their hydraulic parameters are stored in the database) and which of the pumping tests should be interpreted or re-interpreted to ensure their quality.

The analysis and interpretation of the selected pumping test data was the later step. MJ-Pumpit (see section "MJPumpit") was used to interpretate the selected pumping tests data. To facilitate the analysis, the optimal models used to obtain hydraulic parameters were selected with the aid of the automatic plots semi-log, log-log of measure data and diagnostic plots. In this case, Fig. 2 illustrates the Barker model (Barker 1988) with the initial values of transmissivity, storativity, well pumping storage and skin factor. After the evaluation of the results and optimal fit (Fig. 3), the parameters values obtained were exported into the GIS environment to visualize them together with old interpretations and other tests.

Finally, the last step was to create variability map of the parameter analyzed. The Hydrogeological Test Analysis Tools (section "Hydrogeological test analysis") had allowed creating maps of the parameters analyzed. In this application was analyzed the regional transmissivity (Fig. 6), where the aquifer heterogeneities are displayed.

Furthermore, with the aid of infrastructure layers (e.g., metro lines) superimposed with geology, pumping test interpretation is possible to understand the complexity of the study area at different scales, obviously, depending on the layer resolution. In particular to the MAN1 point, the test is close to an underground tunnel (forty meters approximately from MAN1 point). This kind of underground impervious structures modify the groundwater flow pattern and, therefore, the structure could be considered as a boundary condition during the test. However, compared 
with other tests made near the zone (MAN2 and MANS), its transmissivity values are not considerably different from each other (396 $\pm 74 \mathrm{~m}^{2} /$ day) as shown in Appendix A.

In summary, the three steps, (a) analyze and visualize the spatial variability of the hydraulic parameters, (b) analyze and interpret pumping tests with MJ-Pumpit and (c) create spatial transmissivity variability map, have been applied for the rest of the pumping tests without previous interpretations (see Appendix A), demonstrating its usefulness, efficiency and easily understandable manner without neglecting the heterogeneity of the groundwater environment. Nevertheless, in zones where no pumping test data are available in the database, it is possible to complete the analysis with other tools including permeability tools (HEROS toolbar, Velasco et al. 2012a), which can estimate the hydraulic conductivity through textural information.

\section{Conclusions}

An increasing amount of data in hydrogeological studies such as pumping tests requires standardized management for an optimal analysis. These data that are collected (spatial and non-spatial dependents) can easily be integrated and handled by GIS environments. Moreover, the use of GIS platforms reduces the uncertainty of hydraulic parameter estimation because of an accurate knowledge of the aquifer geometry and hydraulic boundaries.

In the present work, we have developed a set of tools for analyzing pumping tests into a GIS environment to support pumping test analysis and groundwater resource management. The software integrates different instruments to collect, manage, analyze, process and represent data derived from pumping tests analyses, through (1) an interface that improves interaction with a pumping test interpretation computer code in a platform that has extensive tools for the analysis and visualization of data (MJPumpit), (2) tools for advanced temporal-spatial analysis built in a GIS environment (HYYH Toolbar) and (3) a geospatial database to maintain complete control of data involved in pumping tests (HYDOR database). This set of modules constitutes an operational and user-friendly analysis platform, which exploits several analysis and visualization tools to ensure optimal results in hydrogeological studies.

With the aid of the HYDOR database, it is possible to standardize and manage the necessary datasets to generate a complete groundwater study in an easy manner. In the same way, pumping test data management can be handled simply by using a screen selection in ArcMAP and by directly exporting the data to MJ-Pumpit. It allows the user to perform additional interpretations by considering different models, accurate geometries (e.g., boundary conditions) of the study area and built-in plotting tools. The interconnection among the MJ-Pumpit, GIS environment and database ensures the proper management of a hydrogeological project.

Acknowledgments This work was supported by the Catalan Industrial Doctorates Plan of the Secretariat for Universities and Research, Ministry of Economy and Knowledge of the Generalitat de Catalunya. The authors would like to thank J. Hidalgo, A. Medina and A. Nardi for their support during the work's development. R. Criollo gratefully acknowledges the financial support from the Grup d'Hidrologia Subterrània, SGR: 2014 SGR 1377.

\section{References}

Bakker M (2009) Wigaem. An analytic element model for periodic flow. Delft University of Technology. Delft, The Netherlands: water resources section, Civil Engineering and Geosciences Delft University of Technology, Delft, The Netherlands

Barker J (1988) A generalised radial-flow model for pumping tests in fractured rocks. British Geological Survey. Wallingford, Oxfordshire, ox 10 8BB, UK

Barlow PM, Moench AF (1999) WTAQ-a computer program for calculating drawdowns and estimating hydraulic properties for confined and water-table aquifers. Water-resources investigations, Northborough, Massachusetts, US

Carbonell JA, Perez Paricio A, Carrera J (1997) MariaJ_IV: programa de calibración automática de ensayos de bombeo: modelos analíticos y numéricos para medios 2-D y 3-D. Universidad Politécnica de Cataluña, Barcelona, 1-106 (interno)

Cheong J-Y, Hamm S-Y, Kim H-S, Ko E-J, Yang K, Lee J-H (2008) Estimating hydraulic conductivity using grain-size analyses, aquifer tests, and numerical modeling in a riverside alluvial system in South Korea. Hydrogeol J 16(6):1129-1143. doi:10. 1007/s10040-008-0303-4

Diputación de Alicante (2006). PIBE 2.0. User manual. https://docs. google.com/file/d/0B1MJStxDOT8ba1YxMjZjY1NDWXM/edit. Accessed 20 February 2014

Duffield GM (1989) AqTestSolv: aquifer test. Summary of aquifer test solutions. AqtestSolv. Virginia, US. http://www.aqtesolv. com/summary_of_solutions.htm. Accessed 30 January 2014

EMRL (2004) Groundwater modeling system reference manual, Version 5.0. Environmental modeling research laboratory, Provo, Utah

ESRI (2004) ArcGIS desktop developer guide: ArcGIS 9.1. ESRI, Redlands, US

Geo\&soft (1993) Well32 Software developed by geo\&soft. http:// www.geoandsoft.com/. Accessed 20 Feb 2014

Halford KJ, Kunianksy EL (2004) USGS OFR 02-197 Spreadsheets for the analysis of aquifer pumping and slug test data. USGS. http://pubs.usgs.gov/of/2002/ofr02197/. Accessed 19 February 2014

Hemker K, Post V (2009) MLU for windows well flow modeling in multilayer aquifer systems UNESCO edition aquifer and pump test analysis software MLU for windows

Johnson GS, Cosgrove DM (2001) RADFLOW: a numerical model for pumping test analysis. http://www.if.uidaho.edu. Accessed 30 January 2014

Jurado A, Gago-Ferrero P, Vàzquez-Suñé E, Carrera J, Pujades E, Díaz-Cruz MS, Barceló D (2014) Urban groundwater contamination by residues of UV filters. J Hazard Mater 271:141-149. doi:10.1016/j.jhazmat.2014.01.036 
Maidment DR (2002) Arc hydro: GIS for water resources. ESRI Press, Redlands

Maidment DR (2005) CUAHSI hydrologic information systems symposium. A data model for hydrologic observations Austin, Texas

Microsoft (2014) Microsoft Developer Network online documentation (MSDN Library October 2014)

Molano C (2013) 2013 William A. McEllhiney distinguished lecture series in water well technology-groundwater spreadsheets: efficient and practical resource for solving simple and complex flow, pollution, and environmental problems. In: 2013 NGWA groundwater expo and annual meeting. Ngwa

Renard P (2003) Hytool: a hydrogeological toolbox. University of Neuchâtel, Switzerland

Rogiers B, Mallants D, Batelaan O, Gedeon M, Huysmans M, Dassargues A (2012) Estimation of hydraulic conductivity and its uncertainty from grain-size data using GLUE and artificial neural networks. Math Geosci 44(6):739-763. doi:10.1007/ s11004-012-9409-2

Röhrich T, Waterloo Hydrogeologic (2002). AquiferTest Pro. Pumping test and slug test analysis software. Schlumberger water services. http://www.swstechnology.com/groundwater-software/ pumping-test-analysis/aquifertest-pro. Accessed 18 February 2014

Rumbaugh D, Rumbaugh J (1997) AquiferWin32. Pumping test analysis. Environmental Software Online. http://www.groundwa tersoftware.com/aquiferwin32.htm. 30 January 2014

Serrano-Juan A, Vázquez-Suñé E, Alcaraz M, Ayora C, Velasco V, Criollo R, Scheiber L (2015) Using spreadsheets and VBA to reuse, customize and extend hydrogeological software. Technical report

Strassberg G (2005) A geographic data model for groundwater systems. Dissertation, University of Texas, Austin

UPC (2002). Ephebo $1.1 \mathrm{rev} 2$. Developed by Department of Geotechnical Engineering and Geo-Sciences, BarcelonaTech, UPC

Vázquez-Suñé, E. (2003). Urban Groundwater. Barcelona City Case Study. Universitat Politècnica de Catalunya. http://www.tdx.cat/ handle/10803/6232. 30 January 2014
Vázquez-Suñé E, Sánchez-Vila X, Carrera J (2005) Introductory review of specific factors influencing urban groundwater, an emerging branch of hydrogeology, with reference to Barcelona. Spain Hydrogeol J 13(3):522-533. doi:10.1007/s10040-004$0360-2$

Velasco V (2013) GIS-based hydrogeological platform for sedimentary media. Universitat Politècnica de Catalunya. http://www. tdx.cat/handle/10803/135005. 30 January 2014

Velasco V, Cabello P, Vázquez-Suñé E, López-Blanco M, Ramos E, Tubau I (2012a) A sequence stratigraphic based geological model for constraining hydrogeological modeling in the urbanized area of the Quaternary Besòs delta (NW Mediterranean coast, Spain). Geologica Acta 10(4):1-20. doi:10.1344/105. 000001757

Velasco V, Gogu R, Vázquez-Suñé E, Garriga A, Ramos E, Riera J, Alcaraz M (2012b) The use of GIS-based 3D geological tools to improve hydrogeological models of sedimentary media in an urban environment. Environ Earth Sci. doi:10.1007/s12665-012$1898-2$

Velasco V, Tubau I, Vázquez-Suñé E, Gogu R, Gaitanaru D, Alcaraz M, Serrano-Juan A, Fernàndez-Garcia D, Garrido T, Fraile J, Sanchez-Vila X (2014) GIS-Based Hydrogeochemical Analysis Tools (Quimet). Comput Geosci. doi:10.1016/j.cageo.2014.04. 013

Vesselinov V (2009) http://www.ees.lanl.gov/staff/monty/codes/wells

Vukovic M, Soro A (1992) Hydraulics and water wells: theory and application. Water Resources Publications, Highlands Ranch, Littleton

Yang YCE, Lin YFF (2011) A new GIScience application for visualized natural resources management and decision support. Trans GIS 15:109-124. doi:10.1111/j.1467-9671.2011.01267.x

Zhan H, Wang LV, Park E (2001) On the horizontal-well pumping tests in anisotropic confined aquifers. J Hydrol 252(1-4):37-50. doi:10.1016/S0022-1694(01)00453-X 